\title{
EDUCAÇÃO PATRIMONIAL E APRENDIZAGEM HISTÓRICA: PERCURSOS EPISTEMOLÓGICOS NA HISTÓRIA ENSINADA
}

\author{
HERITAGE EDUCATION AND HISTORICAL LEARNING: \\ EPISTEMOLOGICAL COURSES TAUGHT IN HISTORY
}

Jaqueline Aparecida Martins Zarbato ${ }^{1}$

\begin{abstract}
RESUMO: Este artigo pretende abordar as reflexões da educação patrimonial como contributo nas aulas de História da Educação Básica. Para tal, metodologicamente este artigo estrutura-se em realizar a análise sobre as concepções teóricas que norteiam a Educação Patrimonial como campo de estudo, assim como a dinâmica que imprime a produção do conhecimento histórico. Analisando o embricamento entre as concepções patrimoniais e o ensino de História, pontuando, desta maneira, a experiência realizada com estudantes de uma escola pública, no interior de Mato Grosso do Sul.
\end{abstract}

Palavras-chave: Educação Patrimonial. Ensino de História. Alfabetização Histórica.

\begin{abstract}
This article aims to address the reflections of heritage education as a contribution in the Basic Education history lessons. To this end, methodologically this article is structured to perform the analysis of the theoretical concepts that guide heritage education as a field of study, as well as the dynamics that prints the production of historical knowledge. Analyzing the interweaving of the equity concepts and teaching history, punctuating this way, the experiment conducted with students from a public school in the interior of Mato Grosso do Sul.
\end{abstract}

Keywords: Heritage Education. Teaching History. Historical Literacy.

1 Professora Adjunta em História na Universidade Federal de Mato Grosso do Sul (UFMS). Doutora em Educação pela Universidade Federal de Santa Catarina (UFSC). 


\section{Introdução}

Folheava o livro Photographias de Lisboa 1900, de Marina Tavares Dias, quando parei numa imagem que tinha algo de muito familiar - e, ao mesmo tempo, algo de profundamente distante das minhas memórias. É uma fotografia de um chafariz de pedra, daqueles que existem em várias zonas de Lisboa. Mas havia neste qualquer coisa que eu reconheceria mesmo que apenas 0 vislumbrasse: olhei para ele todos os dias durante pelo menos 20 anos. O chafariz da Rua de Entrecampos fica junto à casa onde cresci, encostado à linha do comboio e, hoje, em frente do edifício da EDP que um dia ali despontou, demasiado grande para tudo o que o rodeava. Na parede de um dos seus "braços" estão cartazes de publicidade antigos - Licor Cointreau, Aguas Fuente Nueva, Odol, o melhor para os dentes. E, à frente, duas carroças com grandes rodas de madeira, puxadas por burros e carregadas até ao limite com trouxas de roupa lavada. Montadas em cima das trouxas, as lavadeiras saloias, de saias compridas e lenços na cabeça, lançam ao fotógrafo um olhar entre a curiosidade e a suspeita. (COELHO, 2015).

Começo este artigo com a crônica "Rua Entrecampos, Portugal", em que o autor narra, a partir de suas lembranças, exaltadas num livro de fotografias, as minúcias e as táticas cotidianas de um tempo, a relação com o patrimônio cultural, e as estratégias culturais das pessoas que circulavam na rua Entrecampos, em Portugal. E, então, perpasso o olhar no contexto cultural brasileiro, para as nossas cidades, praças, ruas, lugares, edificações, e as muitas lembranças e histórias escondidas ou silenciadas nas 'vielas', nos casarões, nas fotografias, que remontam o entrelaçar de diferentes culturas que fundamentam o patrimônio cultural brasileiro.

Abordar a importância do patrimônio e memória na constituição da história no Brasil, nos remete a inserção nos anos 1930, no governo de Vargas, com a institucionalização do SPHAN (Sistema de Patrimônio Artístico e Nacional), posteriormente chamado de IPHAN (Instituto Nacional de Patrimônio Artístico Nacional), os quais possuem o intuito de preservar, difundir, produzir conhecimento sobre os elementos patrimoniais, cultura material e imaterial e educação patrimonial. As determinações sobre a preservação, socialização e difusão do patrimônio cultural material e imaterial, baseiam-se nas transformações ao longo do tempo, a partir do decreto-lei n 25, de 20 de 
novembro de 1937, promulgado pelo presidente Getúlio Vargas; bem como da difusão do artigo 216 da constituição de 1988, e a divulgação do decreto-lei n 3.551 de 04 de agosto de 2000, que "institui o registro de bens culturais de natureza imaterial que constituem o patrimônio cultural brasileiro, criando o Programa Nacional do Patrimônio Imaterial" (BRASIL, 2000). Mas, esses patrimônios, materiais e imateriais, a quem importa preservar? Descreve que histórias e memórias?

Essas e outras inquietações emergem ao nos debruçarmos sobre a relação entre o patrimônio cultural e a história ensinada, por isso, enveredamos por analisar essas questões a partir da metodologia da Educação Patrimonial. As ações com a Educação patrimonial visaram apontar principalmente práticas culturais que estão ficando obsoletas nos diálogos entre os membros de uma mesma região. Assim como os elementos patrimoniais, como monumentos que representam as identidades de determinados grupos culturais.

Assim, a partir de um projeto de pesquisa ${ }^{2}$, realizamos a investigação sobre a importância do patrimônio cultural no ensino de história, compreendendo a necessidade de fundamentar as práticas de preservação, manutenção de elementos patrimoniais a partir de diferentes interpretações de textos, fontes, imagens, narrativas e ações educativas. Visamos analisar a concepção patrimonial não como um elemento homogeneizador das práticas culturais, mas como um referencial histórico relacionado a memória de diferentes grupos e sua contribuição na história das pessoas, das cidades, das próprias crianças, uma vez que reconhecer os espaços históricos e a relação com a sua vida, contribui para a formação da consciência histórica.

A Educação Patrimonial, tradução do Heritage Education - expressão inglesa, surge no Brasil em meio a importantes discussões acerca da necessidade de se aprofundar o conhecimento e a preservação do Patrimônio HistóricoCultural. Foi, exatamente, em 1983, que se iniciam, efetivamente, as ações de

2 O projeto de pesquisa: Recontando a história de Tres Lagoas/MS: narrativas e utilizações da Educação Patrimonial nas aulas de história, está sendo desenvolvido desde 2014. Assim, realizamos entrevistas, seleção de imagens e textos sobre a história regional e a relação com a cidade, saídas de campo com os estudantes da escola pública com a fundamentação da Educação Patrimonial. 
Educação Patrimonial por ocasião do $1^{0}$ Seminário sobre o "Uso Educacional de Museus e Monumentos", no Museu Imperial de Petrópolis, RJ. A Educação Patrimonial, por princípio, trata-se de um processo permanente e sistemático de trabalho educacional, centrado no Patrimônio Cultural como fonte primária de conhecimento individual e coletivo (HORTA, 2004).

A Educação Patrimonial, que foi instituída pelo IPHAN, visa provocar situações de aprendizado sobre o processo cultural e, com o conhecimento apropriado, fundamentar, junto aos estudantes, diferentes análises sobre a sua própria vida pessoal e coletiva, configurando-se como "um instrumento de alfabetização cultural, que possibilita ao indivíduo fazer a leitura do mundo que o rodeia, levando-o à compreensão do universo sociocultural e da trajetória histórica-temporal em que está inserido" (HORTA, 2004, p 34).

Neste processo da produção do conhecimento do patrimônio histórico, as motivações se dão pela compreensão de qual memória queremos legar aos grupos e os elementos culturais que serão lembrados. Assim, ao propor a metodologia da educação patrimonial, concebemos a necessidade de inserir as discussões sobre as modificações no espaço urbano, nas ruas, nos bairros e, até mesmo, no sentimento de pertencimento e de compartilhamento de costumes e tradições herdadas dos grupos culturais. Deste modo, a educação patrimonial pode auxiliar a entender quem somos, o que fazemos, e para onde vamos, mesmo que não nos identifiquemos com o que este bem patrimonial evoca. A preservação do patrimônio histórico está ligada a questão da cidadania, fato que "[...] implica em reconhecer que, como cidadãos, temos o direito à memória, mas também o dever de contribuir para a manutenção desse rico e valioso acervo cultural de nosso país" (ORIÁ, 2005, p.140).

Para Oliveira (2008. p. 98) o patrimônio histórico é concebido como

[...] uma produção cultural [que] encerra em si características que favorecem, facilitam a relação de ensino/aprendizagem por parte de quem o utiliza, por parte daqueles que o usam como fonte documental para a obtenção de conhecimento a respeito de uma determinada época, de determinadas condições socioeconômicas de produção de determinado bem, das relações de poder que demonstram que tal imóvel, por pertencer a uma determinada parcela mais abastada da sociedade, então, foi construído com material de melhor qualidade, pode explicar continuidades e mudanças ocorridas em determinados locais, entre várias outras potencialidades que estes documentos apresentam. 
Ao fundamentar a abordagem sobre cultura e patrimônio na História ensinada, envolve-se os elementos vinculados a função propedêutica da História, respondendo as lacunas impostas em diferentes períodos históricos sobre a representatividade de diferentes saberes históricos. Cultura histórica não é mais do que a consciência histórica no nexo prático da vida. Com este termo, condicionalidades, funções objetivas e, com elas, práticas da vida social, são adicionadas aos elementos subjetivos da consciência no campo de visão da didática da história (RÜSEN, 2012, p. 130).

A 'percepção' da experiência histórica, de desvendamento da mutação temporal do mundo externo e interno, de uma sensibilidade para a diferença pessoal ou para a alteridade, tem como exemplo o museu histórico, pois nele utilizamos um modelo interpretativo específico do curso de tempo. A cultura, como formação de sentido, sempre tem efeito sobre as realizações da vida prática humana e também pode ser ali identificada.

Por este viés a Educação Histórica agrega as complexidades da análise da formação de sentido, fundamentadas por Rüsen (2014) quando aponta as dimensões das práticas culturais e suas narrativas. A análise do patrimônio pode envolver as três dimensões da cultura histórica:

a) estética: trata-se do percebido, daquilo que é significativo no histórico. Inter relação entre as formas de representação e as funções de orientação, constituição histórica de sentido. b) Cognitiva: trata de ciência, trata-se das diretrizes de interpretação e os métodos de elaboração da experiência. c) político-moral ou prático: contém o político, o técnico, o moral - inter relações ente as carências de orientação cultural.

O entrelace entre as dimensões na produção do sentido histórico apresenta a cultura histórica como processo de aprendizado. Nesses tempos em que as pessoas não se reconhecem mais nos lugares em que habitam, em que tudo é fluído, em que a democratização, massificação, mediatização, no dizer de Pierre Nora (1993, p. 7), provoca uma "[...] oscilação cada vez mais rápida de um passado definitivamente morto, a percepção global de qualquer coisa como desaparecida - uma ruptura de equilíbrio". Realidade que Horta (2004, p.12) definiu como "agnosia social", a incapacidade de reconhecer o universo que nos rodeia devido à carência de habilidades de interpretação, representação e reconhecimento desta realidade, pertencentes ao pensamento e a memória. 
O conhecimento crítico e a apropriação consciente pelas comunidades do seu patrimônio são fatores indispensáveis no processo de preservação sustentável desses bens culturais, assim como no fortalecimento dos sentimentos de identidade e cidadania. A Educação Patrimonial é um instrumento de "alfabetização cultural" que possibilita ao indivíduo fazer a leitura do mundo que o rodeia, levando-o à compreensão do universo sociocultural e da trajetória histórico-temporal em que está inserido. Os patrimônios culturais, segundo Gonçalves (2002, p.121-122):

São estratégias por meio das quais grupos sociais e indivíduos narram sua memória e sua identidade, buscando para elas um lugar público de reconhecimento, na medida mesmo em que as transformam em 'patrimônio'. Transformar objetos, estruturas arquitetônicas e estruturas urbanístícas em patrimônio cultural significa atribuir-Ihes uma função de 'representação', que funda a memória e a identidade. [...] Os patrimônios são, assim, instrumentos de constituição de subjetividades individuais e coletivas, um recurso à disposição de grupos sociais e seus representantes em sua luta por reconhecimento social e político no espaço público.

\section{Ação de educação patrimonial: investigação e aprendizagem histórica na escola básica}

Ao investigar as dimensões do patrimônio e a relação com a aprendizagem histórica, adotamos a metodologia da educação patrimonial, atentando para os objetivos históricos estabelecidos, os pressupostos teóricos que fundamentam a instituição e os públicos alvos da ação pedagógica. Entretanto, mesmo compreendendo que ao longo de nossa configuração histórica os patrimônios são determinados por alguns grupos que, por sua vez, destacam quais as edificações, prédios, festas e tradições são concebidas como bens patrimoniais, buscamos, a partir das práticas educativas, a inserção de outras interpretações sobre os bens patrimoniais. Isso porque, a preservação, conservação e conhecimento histórico só são possíveis deslocando o conceito de pertencimento, inserindo-os nas efetivas atuações, apropriações e na circulação sobre cada elemento patrimonial. Desta maneira, defende-se que 
[...] o Patrimônio Cultural de uma sociedade, de uma região ou de uma nação é bastante diversificado, sofrendo permanentes alterações, e nunca houve ao longo de toda a história da humanidade critérios e interesses permanentes e abrangentes voltados à preservação de artefatos do povo, selecionados sob qualquer ótica que fosse (LEMOS, 1987, p.21).

Segue-se, portanto, essa perspectiva de defender a diversificação de fontes e artefatos históricos, assim como os diferentes usos, adaptações e apropriações dos bens patrimoniais pelas pessoas. Logo, ao propor a abordagem da Educação Patrimonial prima-se por construir uma análise educacional, conscientizadora, de forma coletiva, com a finalidade de provocar o envolvimento e conhecimento cultural, valorizando o patrimônio histórico e suas manifestações culturais. Para Dias et al. (2006, p. 73), uma das características mais relevantes do patrimônio é "[...] ser tomado como referência para a construção de identidades culturais pelas mais diversas estruturas sociais e mesmo pelos cidadãos, em nível individual, de forma a converter-se no capital simbólico da sociedade". Esse fator é um elemento social de grande caráter subjetivo e, como tal, esteve exposto a importantes manipulações em função de determinados interesses, de fundo político ou ideológico, para justificar alguns fatos históricos, reclamar territórios ou explicar teorias de fundo nacionalista, entre outras.

Desta forma, envolve práticas educativas que contribuam para 0 reconhecimento da diversidade cultural no espaço ao qual se vive, em que cada manifestação cultural passa a ter significação social. Com essa concepção, o patrimônio cultural brasileiro circunscreve-se na valorização de bens patrimoniais considerados diversos. Assim, como destaca Horta (1999, p 07), no "Guia Básico de Educação Patrimonial":

Existem outras formas de expressão cultural que constituem o patrimônio vivo da sociedade brasileira: artesanatos, maneiras de pescar, caçar, plantar, cultivar e colher, de utilizar plantas como alimentos e remédios, de construir moradias, a culinária, as danças e músicas, os modos de vestir e falar, os rituais e festas religiosas e populares, as relações sociais e familiares, revelam os múltiplos aspectos que pode assumir a cultura viva e presente de uma comunidade.

As formas de expressão cultural que pontuamos trabalhar o patrimônio, pautam-se por essa proposta do Guia Básico de Educação Patrimonial, lançado 
pelo IPHAN. Neste processo de inserção do patrimônio cultural no ambiente escolar, objetivamos desenvolver com os estudantes a busca de sua identidade através da herança cultural que o representa. Isso porque a educação patrimonial promove um melhor aprendizado para a questão cultural, despertando o interesse em conhecer as identidades que constituíram as manifestações das histórias e as composições dos lugares de memória. Um dos elementos, que surge neste processo de conhecimento patrimonial, é a investigação sobre a história local, a qual apresenta as diferentes formas de vida, no presente e no passado, circunscritas também às diretrizes curriculares, tanto que, nos Parâmetros Curriculares Nacionais:

A proposta para os estudos históricos é de favorecer o desenvolvimento das capacidades de diferenciação e identificação, com a intenção de expor as permanências de costumes e relações sociais, as mudanças, as diferenças e as semelhanças das vivências coletivas, sem julgar grupos sociais, classificando-os como mais "evoluídos" ou "atrasados". (BRASIL, 2000).

Neste sentido, pode-se dizer que a utilização das vivências, representações, identificações, em que o patrimônio se constitui, e é constituído, faz parte das ações educativas na escola e na sociedade. Assim, as ações com educação patrimonial no espaço escolar contemplam uma diversidade de fontes históricas. Nos deteremos, aqui, na análise sobre o espaço em que vivem os estudantes da escola pública, em que foi realizada a pesquisa e atividade de educação patrimonial.

A Educação Patrimonial na Educação Histórica poderia se enquadrar no patamar das experiências e das investigações, e contribuir para consolidar a investigação no Ensino de História, porque estimula e eleva a identidade do aluno ao permitir que suas crenças, os saberes guardados na família, na comunidade, sejam considerados e relativizados, frente a outras experiências do passado e do presente (EHLKE, 2008). Ao propor a construção de uma tipologia, no plano metodológico, sobre as diferenças culturais, enquanto construto hipotético que, em simultâneo, evite os constrangimentos de uma noção de cultura fixa e fechada, mas que, da mesma forma, não se prenda nas malhas (relativistas) das diferenças culturais, Rüsen (2007) insere a abordagem 
intercultural de uma forma indelével no debate sobre consciência história, quer ao nível da reflexão filosófica, quer ao nível da investigação empírica.

$\mathrm{Na}$ aula de História, os alunos são confrontados com a ideia de relação entre as pessoas, bem como com as formas pelas quais essa relação influenciou a diversidade no passado e no presente. O quadro conceitual que se tem vindo a discutir, parece encontrar-se para além da natureza da História, contudo a sua progressiva inclusão nas preocupações e propostas dos filósofos da História, e dos investigadores em Educação Histórica, sugere a possibilidade de uma proximidade às ideias metahistóricas na perspectiva da definição apresentada por Peter Lee (2001).

Logo, inserimos na análise o ato de narrar, compreendido como uma prática. Ele representa um processo específico de formação de sentido, no qual se trata de dar conta de uma experiência temporal mediante interpretação. Por isso, a importância em fundamentar nossa análise nas concepções da Educação Histórica, uma vez que ela insere elementos que contribuem para que os alunos compreendam que a História é um conhecimento específico, estando imersa no mundo cotidiano em que os sujeitos se relacionam. Impulsionado pela perspectiva de se repensar a História como utilidade para a vida, e também por assumir a importância do sujeito no processo de construção do conhecimento, a Educação Histórica surge como uma linha de investigação que pretende analisar, compreender, e discutir as premissas em torno da formação histórica dos alunos.

\section{Investigando o patrimônio cultural local e o pertencimento histórico com crianças de uma escola pública}

A intenção em problematizar os lugares de memória, assim como os bens patrimoniais locais em Três Lagoas, Mato Grosso do Sul, deu-se a partir das aulas de História numa escola pública, em que os estudantes afirmaram desconhecer os elementos patrimoniais que fazem parte da história da região e da cidade. $\mathrm{E}$, em algumas situações, confundiram patrimônio cultural com patrimônio financeiro. Entre as discussões sobre a memória e a história, 
surgiram as inquietações e dúvidas sobre $o$ que representam os bens patrimoniais para as pessoas e a cidade.

A partir desse desconhecimento, partimos da concepção da Educação Patrimonial de que o reconhecimento contribui para a preservação e manutenção das diferentes identidades de um povo, de uma cultura. E que, se os sujeitos não se sentem representados, ou mesmo não reconhecem a importância, não se preocupam em preservar os elementos patrimoniais. Com a intenção de fomentar as diferentes representações e interpretações que as crianças possuem sobre como o patrimônio cultural, local e regional, configura e influencia o cotidiano delas, iniciamos as atividades na escola.

As ações da Educação Patrimonial na cidade de Três Lagoas, Mato Grosso do Sul, foram executadas com as crianças do $8^{\circ}$ ano do Ensino Fundamental, da Escola Estadual Padre João Tomes, situada no bairro Vila Piloto. Bairro construído nos idos de 1960, quando da instalação da hidrelétrica que separa os estados de Mato Grosso do Sul e São Paulo.

O bairro Vila Piloto, por si só, apresenta inúmeras questões que merecem análise histórica, porém na sistematização com os estudantes, evidenciamos as concepções do espaço urbano, suas ruas e bairros que foram perdendo a significação histórica, em meio ao processo de urbanização e modernização da cidade. A ideia de pertencimento, não como uma necessidade de se identificar como um sujeito sem visão crítica acerca do espaço, tem sido uma tônica em nossas análises. Assim, o lugar em que vivem as pessoas e a importância das edificações, costumes e tradições, são compreendidas como processos de alfabetização histórica acerca do universo cultural que nos forma, e do qual temos lembranças. Seu desaparecimento, por sua vez, é entendido como perda das identidades culturais herdadas. Mas, como esse bairro fica afastado do centro, poucas crianças conhecem os elementos patrimoniais históricos da cidade, bem como a representação deles.

Por isso, realizamos aulas oficinas com a turma, analisando alguns bens culturais locais que são considerados patrimônio histórico regional e local, uns tombados, outros não. E, nesse processo, questionando com as crianças o processo de identificação e estranhamento sobre os ditos bens patrimoniais. Para 
tal, iniciamos a atividade com o questionamento sobre o reconhecimento prévio do que é um patrimônio.

As ações de ensino e aprendizagem levaram em conta os roteiros, baseados no Guia de Educação Patrimonial, elaborado pelo IPHAN. Definimos alguns elementos para a investigação sobre os monumentos e edificações que são caracterizados como patrimônios regionais e locais. Pesquisamos, no arquivo histórico municipal estadual, as imagens antigas sobre os monumentos e edificações históricas que poderiam fundamentar nossa ação de educação patrimonial. A proposta visou, a partir das narrativas, possibilitar a todos/as conhecer as concepções dos sujeitos (alunos, inclusivamente) sobre:

a) significados atribuídos ao mundo presente e passado. b) sentidos de mudança (progresso ou declínio linear ou complexo, dialética, ciclo, permanências ou rupturas), c) papel da História na orientação temporal (relações entre passado, presente e expectativas de futuro) no plano coletivo e no plano individual (como se posiciona o sujeito na História?), d) valores de (inter)culturalidade em situações de diálogo, de tensão ou de conflito. (BARCA, 2012, p. 39).

Os sentidos e significados, sobre patrimônio material e imaterial, impulsionaram a reflexão sobre a importância da Educação Patrimonial estar articulada ao ensino de História. Isso porque, a Educação Patrimonial contribui para adentrarmos à história local, de forma que possamos participar do processo de reconhecimento, valorização e preservação do patrimônio. A preservação da memória é essencial para a valorização da identidade, e da cidadania cultural, em determinado lugar, e situada num determinado tempo histórico. Alguns elementos históricos são definidos como primordiais para a história local, construindo referenciais para a memória coletiva, a qual não é "[...] somente uma conquista, como também um instrumento e um objeto de poder" (LE GOFF, 1996).

Nesse processo de valorização da memória coletiva, os monumentos se configuram como legitimadores da rememoração e valorização do passado, constituindo-se como elementos que agregam a política do que deve ser lembrado. Então, se esquece que todos têm direito à memória, uma vez que o passado reconstituído justificava a legitimação de determinados conjuntos de 
interesses. Para Dias et al. (2006, p. 73), uma das características mais relevantes do patrimônio é "[...] ser tomado como referência para a construção de identidades culturais pelas mais diversas estruturas sociais e mesmo pelos cidadãos, em nível individual, de forma a converter-se no capital simbólico da sociedade". Esse fator é um elemento social de grande caráter subjetivo e, como tal, esteve exposto a importantes manipulações em função de determinados interesses, de fundo político ou ideológico, para justificar alguns fatos históricos, reclamar territórios ou explicar teorias de fundo nacionalista, entre outras.

Desta forma, promover a preservação e valorização desses bens culturais, exige aprofundamento no campo do ensino de História, pois envolve ações educativas que possam viabilizar a aproximação entre os sujeitos que estudam e aprendem, num processo que promova, no ambiente escolar, uma possibilidade de leitura da memória coletiva, dos monumentos e das relações que se estabelecem entre eles, de forma analítica e crítica. Conforme Horta, Grunberg e Monteiro (1999, p. 6),

O conhecimento crítico e a apropriação consciente pelas comunidades do seu patrimônio são fatores indispensáveis no processo de preservação sustentável desses bens culturais, assim como no fortalecimento dos sentimentos de identidade e cidadania. A Educação Patrimonial é um instrumento de "alfabetização cultural" que possibilita ao indivíduo fazer a leitura do mundo que o rodeia, levando-o à compreensão do universo sociocultural e da trajetória histórico-temporal em que está inserido. Este processo leva ao reforço da auto-estima dos indivíduos e comunidades e à valorização da cultura brasileira compreendida como múltipla e plural.

Segundo o Guia Básico de Educação Patrimonial, lançado em 1999, pelo Instituto do Patrimônio Histórico e Artístico Nacional (IPHAN), a Educação Patrimonial trata-se de

[...] um processo permanente e sistemático de trabalho educacional centrado no Patrimônio Cultural como fonte primária de conhecimento e enriquecimento individual e coletivo. Busca levar as crianças e adultos a um processo ativo de conhecimento, apropriação e valorização de sua herança cultural, capacitando-os para um melhor usufruto destes bens, e propiciando a geração e a produção de novos conhecimentos, num processo contínuo de criação cultural. (HORTA; GRUNBERG; MONTEIRO, 1999, p.7). 
Aquilatando a questão de se problematizar e situar os alunos no espaço/tempo de dado monumento, bem como a preocupação em contribuir com a reflexão sobre os assuntos da história local pode levá-los a refletir sobre evidência patrimonial. A análise de ideias prévias e da relação com os conhecimentos produzidos acerca da vivência do seu lugar com o patrimônio da cidade, fundamenta a relação do lugar com a interculturalidade, o patrimônio, para assegurar a verificação da progressão dos conhecimentos dos alunos. Como apresenta Helena Pinto (2012, p. 198)

A utilização de fontes patrimoniais no ensino de História, nomeadamente em contexto, não é tão frequente como seria desejável, como mostraram diversos estudos de Educação Histórica. Para que isso se faça de forma consistente, é necessário promover uma educação patrimonial a um nível fundamentado: proporcionar recursos e atividades desafiadoras, usar fontes patrimoniais de forma a contribuir para o desenvolvimento da compreensão dos conceitos históricos pelos alunos e a interpretação dos contributos culturais, sociais e econômicos de diversos grupos nas suas comunidades.

A expressão Educação Patrimonial, concebida como uma proposta metodológica e um tipo de ação social, visa analisar os bens culturais como fonte histórica, atrelando a ação direta na vida prática do sujeito, recuperando as conexões entre as gerações, promovendo a apropriação pelas comunidades e pelos estudantes de sua herança cultural, reforçando e desenvolvendo na escola, nos sistemas de educação formal e não-formal, com crianças e adultos [...] (HORTA, 2000, p. 35). Deste modo, a ação de Educação Patrimonial do IPHAN está estruturada em três eixos de atuação: inserção do tema Patrimônio Cultural na educação formal; gestão compartilhada das ações educativas; instituição de marcos programáticos no campo da Educação Patrimonial. Assim, a Educação Patrimonial é componente importante nos processos de identificação, reconhecimento e preservação do patrimônio cultural. Pierre Nora (1993, p. 7) destaca que:

A curiosidade pelos lugares onde a memória se cristaliza e se refugia está ligada a este momento particular da nossa história. Momento de articulação onde a consciência da ruptura com o passado se confunde com o sentimento de uma memória esfacelada, mas onde o esfacelamento desperta ainda memória suficiente para que se possa colocar o problema de sua encarnação. O sentimento de continuidade torna-se residual aos 
locais. Há locais de memória porque não há mais meios de memória.

Atrelar o reconhecimento dos 'lugares de memória', das edificações, do sentimento de pertencimento contribui para a preservação e valorização dos bens culturais, mas, também, exige aprofundamento no campo do ensino de História, pois envolve ações didático-educativas que viabilizam a aproximação entre os sujeitos e suas culturas, num processo que promova, no ambiente escolar, uma possibilidade de leitura da memória coletiva, dos monumentos e das relações que se estabelecem entre eles, de forma analítica e crítica. Sobre isso, Pierre Nora afirma ainda que "Se habitássemos ainda nossa memória, não teríamos necessidade de lhe consagrar lugares. Não haveria lugares porque não haveria memória transportada pela história" (NORA, 1993, p. 8-9).

Envolver o conhecimento e reconhecimento cultural dos sujeitos históricos na dinâmica da cidade, foi um dos primeiros passos da atividade com a turma do $8^{\circ}$ ano. Assim, os 25 estudantes iniciaram a investigação a partir do lugar em que vivem, historicizando a Vila Piloto, a qual teve o início da construção no final de 1959 até 1961, considerada como uma forma de organização do, até então, (acampamento) Vila Piloto, nome oriundo do Projeto Piloto da construção de Brasília-DF. A influência da construção da Usina do Jupiá ${ }^{3}$ sobre as origens dos primeiros operários que habitaram a Vila Piloto, portanto, pode ser verificada.

Ao contextualizar a história da Cidade de Três Lagoas/MS, a partir do lugar em que vivem, ou seja, a Vila Piloto, é possível compreender os conhecimentos prévios dos estudantes sobre o patrimônio cultural da cidade. Ao apresentar imagens, o questionamento sobre a história do lugar, as relações de trabalho, de sociabilidade, as festas relacionadas com cotidiano da Vila Piloto, com a cidade e com o Estado de Mato Grosso do Sul, e as trajetórias e subjetividades das pessoas que habitam o bairro, encaminha-se diferentes interpretações e narrativas. Este processo de reconhecimento do que modificou-

3 A Usina Hidrelétrica Engenheiro Souza Dias (Jupiá) foi construída com tecnologia inteiramente brasileira e concluída em 1974. Está localizada no Rio Paraná, entre as cidades de Andradina e Castilho (SP) e Três Lagoas (MS). Essa usina possui 14 unidades geradoras com turbinas Kaplan com potência instalada de $1.551,2 \mathrm{MW}$ e dois grupos turbina-gerador, para serviço auxiliar, com potência instalada de $4.750 \mathrm{~kW}$ em cada grupo. 
se e do que permaneceu na trajetória do lugar, implicam diferentes sentimentos de pertencimento, de negação e manutenção de memória individual e coletiva.

Após a discussão sobre a representação da Vila Piloto, iniciamos a problematização sobre as edificações históricas que as crianças reconheciam como patrimônio cultural, explicitando a sua compreensão do que é um patrimônio, o que representa para eles, como descrevem, e de que maneira podemos narrar sua importância para a cidade. Partimos da concepção da metodologia da Educação Patrimonial, que pode levar os professores a utilizarem os objetos culturais na sala de aula ou nos próprios locais onde são encontrados, como peças "chave" no desenvolvimento dos currículos e não simplesmente como mera "ilustração" das aulas.

Assim, cada grupo de 5 estudantes definiu um bem patrimonial da cidade para realizar sua pesquisa e interpretação. A escolha se deu após a saída de campo no centro da cidade, espaço em que temos o maior número de edificações, praças, igrejas, arquivo público, relógio central, estação ferroviária, etc.

Seguindo a abordagem da Educação Patrimonial, analisamos com as crianças as possibilidades de abordagem sobre um monumento, destacando que o mesmo "é uma edificação ou sítio histórico de caráter exemplar, por seu significado na trajetória de vida de uma sociedade/comunidade e por suas características peculiares de forma, estilo e função" (IPHAN, 1999, p.14). De certa forma, alguns edifícios isolados, sítios ou conjuntos de edificações têm um significado especial para a História do Brasil, como marcos na trajetória nacional. Outros têm uma importância regional ou local (IPHAN, 1999, p. 15). Com essa prerrogativa da importância local, partimos para o centro da cidade de Três Lagoas, identificando, a partir da observação direta e do registro por narrativas, as diferenças entre os bens culturais.

A lógica da atividade visou a preparação dos alunos, em sala de aula, para que a visita ao espaço central da cidade permitisse estimular a observação, introduzir a discussão, e sensibilizá-los em relação ao meio ambiente que os rodeia. Desta maneira, "[...] aprender através do olhar não é necessariamente simples, desenvolver a habilidade da observação e interpretação do que nos rodeia, auxilia na compreensão do mundo; isto requer tempo, prática e um 
esforço consciente que precisa ser desenvolvido através de exercícios e tarefas" (IPHAN, 1999, p 23).

Com isso, as crianças analisaram a Igreja de Santo Antônio, a estação ferroviária e o Relógio Central.

A Igreja Santo Antônio fica localizada no centro da cidade de Três Lagoas, foi construída em 1914, sendo este o santo padroeiro da cidade. Ainda na década de 1910

[...] foi construída a praça da igreja pela comunidade portuguesa da cidade. Arquitetonicamente, a igreja representa uma confluência de estilos. Os ornamentos exteriores e as portas da Igreja Santo Antônio apresentam fortes influências da Arquitetura Românica. Já as paredes e os vitrais em suas janelas têm características da Arquitetura Gótica. Seu interior, por fim, é decorado, remetendo à arquitetura barroca" (FERNANDES, 2015) ${ }^{4}$.

A Igreja tem suas histórias e lendas, uma delas é a história do pretinho aleijado, hoje transformado em lenda:

O Pretinho aleijado, entre outras coisas, era o responsável por tocar o sino da igreja em horas específicas. Sua lenda se iniciou quando, durante um assalto à igreja, foi assassinado pelo assaltante. Desde então, diz-se que o sino da Igreja Santo Antônio toca por si só e que isso seria o espírito do Pretinho aleijado desempenhando seu trabalho (FERNANDES, 2015).

Ao abordar a historicidade que envolve a construção, preservação e lendas em torno da Igreja de Santo Antônio, mostramos a imagem abaixo, disponível no Arquivo Público, e dialogamos sobre a importância desse patrimônio para a cidade. Após o reconhecimento das diferentes histórias e memórias, combinamos a saída de campo com os estudantes, com o objetivo de fazer a investigação sobre os bens patrimoniais e realizar a visita in loco. Um outro bem patrimonial, que é referência histórica na cidade de Três Lagoas, é o relógio central (Figura 1). Construída em 1936, a estrutura do relógio localiza-se no encontro da avenida Antônio Trajano com a rua Paranaíba, e está no ponto há 80 anos.

4 Entrevista com Rodrigo Fernandes, coordenador de Patrimônio Cultural da Prefeitura de Três Lagoas, 2015. 


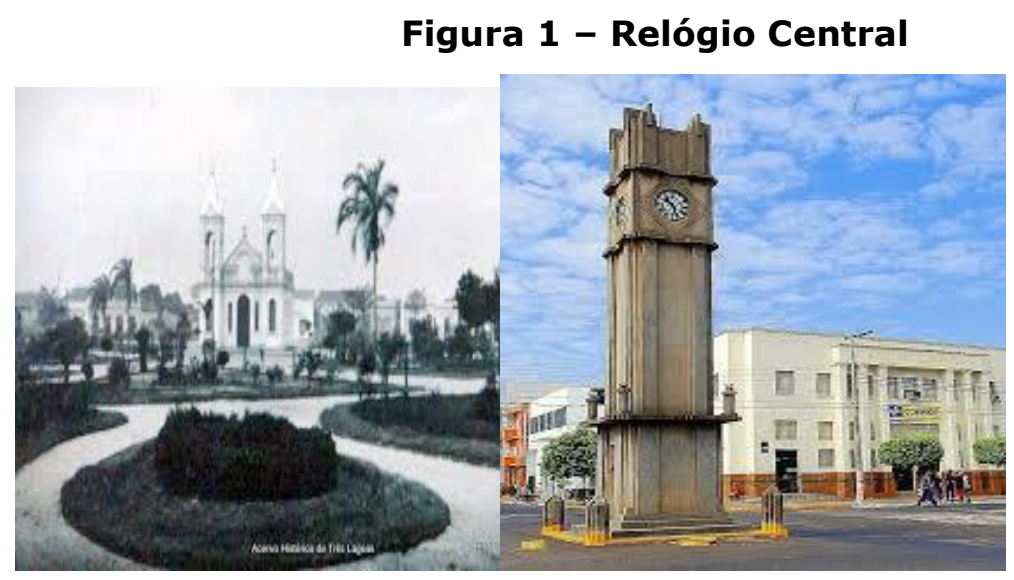

Fonte: Secretaria de Cultura de Três Lagoas/MS. Catálago de fotos históricas.

Após a saída de campo com os estudantes, sob a proposição do aprendizado da Educação Patrimonial, o método investigatório é uma das primeiras capacitações que se pode estimular nos alunos, no processo educacional, desenvolvendo suas habilidades de observação, de análise crítica, de comparação e dedução, de formulação de hipóteses e de solução de problemas colocados pelos fatos e fenômenos observados (HORTA, 1999, p. 3).

Focalizamos em apresentar o espaço em que vivem como propulsor da relação intercultural na cidade, do que sensibiliza os estudantes em relação a manutenção, preservação da memória e dos lugares de memória. Isso porque, na experiência histórica, trata-se sempre de sentido, mas

[...] sobretudo também dos sentidos como porta de entrada do mundo exterior na subjetividade humana. O tempo é experimentado historicamente, mas não simplesmente como transformação e mudança e sim como uma transformação importante para a vida humana, que possui significado, mais exatamente: que precisa ser dotada de significado para que a vida possa prosseguir na mudança experimentada pelo ser humano e pelo mundo" (RÜSEN, 2014, p 182-183).

Desta maneira, cada grupo produziu análises com as suas interpretações sobre os bens patrimoniais visitados (Figuras 2 e 3). A concepção de analisar, visitar e interpretar com suas narrativas faz parte da metodologia da Educação Patrimonial nas aulas de História. 


\section{Figuras 2 e 3 - Análises dos estudantes}
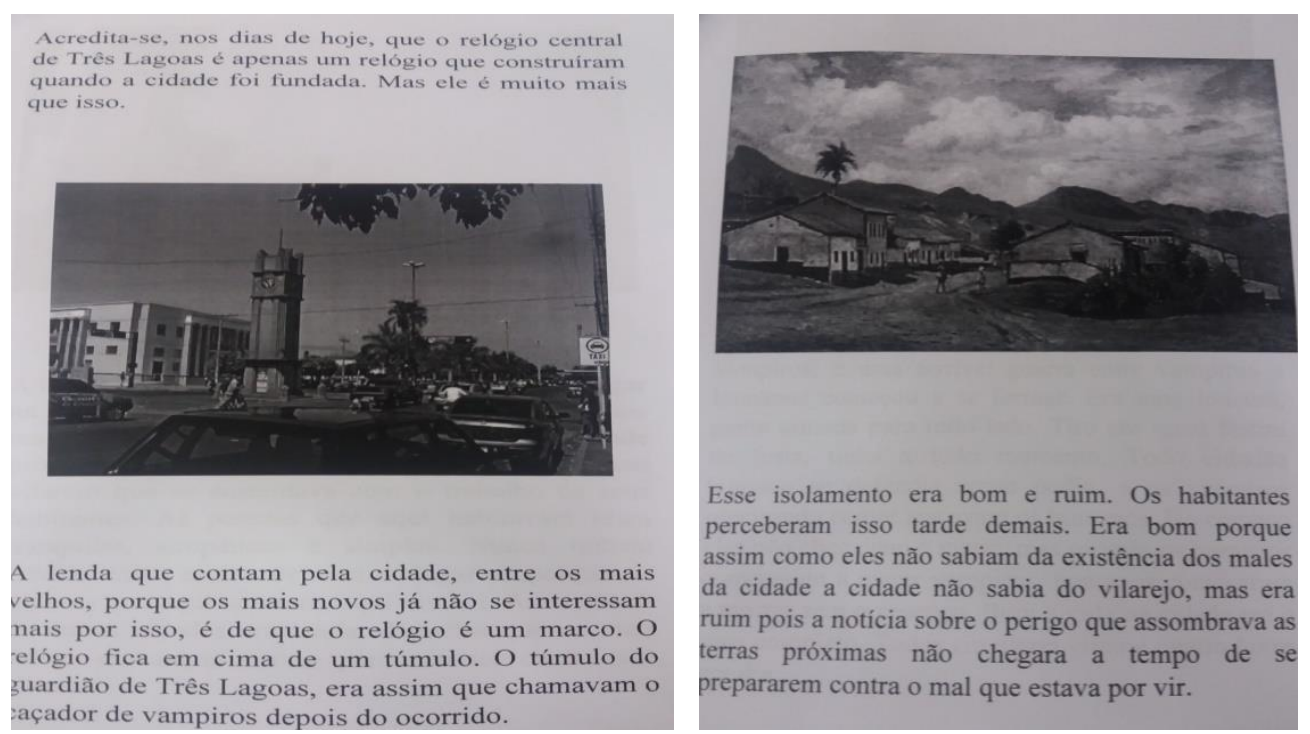

Fonte: Cartilha educativa produzida pelos estudantes. 2016 na pesquisa

Nas narrativas que os adolescentes, em idade entre 12 e 16 anos, realizaram sobre a exploração do patrimônio cultural, percebe-se que eles compreendem que a experiência de viver e preservar os espaços históricos faz parte do que se aprende na História. Como define Vitor, 12 anos: "[...] a história da cidade está atrelada a esses lugares, minha avó falou isso, quando eu contei onde fomos". Ou como relata Mia, de 14 anos: "[...] ao pesquisar os lugares que são históricos na cidade, aprendi que alguns são patrimônios que não podem ser destruídos, porque no século XXI devemos olhar para o passado e recuperar o que significou no século $X X$, por exemplo". E que preservar um monumento, uma edificação, uma festa, uma memória também contribui com a valorização das pessoas de outras gerações. Mauricio, 12 anos, no início da abordagem em sala de aula, questionou: "Professora, pessoas são patrimônios?"

A partir da indagação do estudante, apresentamos as diferentes possibilidades de leitura da História sobre lugares de memória, sobre a vivência das pessoas com os lugares de memória. Ao entrevistar os familiares, Maurício, definiu, que "os velhos da minha família, são nosso patrimônio".

Percebe-se que a memória pode ser um dos elos da ação educativa a partir do patrimônio, pois, segundo Oriá (2005, p 139), 
[...]a memória dos habitantes que faz com que eles percebam, na fisionomia da cidade, sua própria história de vida, suas experiências sociais e lutas cotidianas [...], sem a memória não se pode situar na própria cidade, pois perde-se o elo afetivo que propicia a relação habitante-cidade, impossibilitando ao morador de se reconhecer enquanto cidadão de direitos e deveres e sujeito da história.

As crianças começaram a perceber a relação entre os lugares de memória, as edificações, como o relógio e a Igreja, além de outros que foram analisados como atrelados ao seu cotidiano. Narraram as histórias que envolveram os lugares, como a origem de sua família e as experiências vividas, explicando como era a cidade, os monumentos construídos e destruídos, as praças, a falta de asfalto, as festas do folclore, de carnaval, a lagoa e as sociabilidades. No processo e reconhecimento sobre os bens patrimoniais e o entendimento histórico cada estudante construiu sua interpretação histórica. Como salienta Schmidt (2009), em seu estudo, a "[...] necessidade de se entender a ideia do aluno com uma invenção historicamente determinada, como sujeitos históricos, reflexivos e capazes de construírem conhecimentos e suas próprias identidades". A aprendizagem histórica em que o experimentar, interpretar, orientar e motivar são elementos constitutivos permite que os/as alunos/as tenham noções mais elaboradas, com níveis de compreensão do processo histórico mais amplos, em que utilizam suas interpretações no processo de aprendizagem histórica.

Em relação ao processo de interpretação, percebe-se que as explicações racionais tendem a valorizar as diferentes compreensões dos/as alunos/as. A assimilação de conceitos/temas/conteúdos faz parte do processo da experiência histórica. Assim sendo, não há experiência sem interpretação, mas experiência, ainda assim, é algo diferente da interpretação. Ela exige interpretação, pode modificá-la e até negá-la. Na experiência histórica trata-se sempre de sentido, mas sobretudo também dos sentidos como porta de entrada do mundo exterior na subjetividade humana. O tempo é experimentado historicamente, mas não, simplesmente, como transformação e mudança, e sim como uma transformação importante para a vida humana, que possui significado, mais exatamente "[...] que precisa ser dotada de significado para que a vida possa prosseguir na mudança experimentada pelo ser humano e pelo mundo" (RÜSEN, 2013, p 182183). 
Os estudantes perceberam o que havia mudado, e questionaram como poderiam ajudar a manter a cidade e sua história. Uma das narrativas, a de Lucas, destacou: "[por que] as pessoas que mandam na cidade deixam acabar com as praças, com as coisas que são boas para nós?"

A narrativa dele mesmo, posteriormente, respondeu, apontando que: "nunca perguntam para quem vive na cidade, se este ou aquele prédio, aquela praça, a dança, os espaços que nós frequentamos pode ser modificado, pode ser derrubado, acabado. Dói as vezes, passar num lugar e contar para meus netos, que eu ia lá, que dançava nas tardes de domingo na praça. E a praça não existe mais'.

Nesse processo de análise, visamos envolver as narrativas seguindo uma premissa proposta por Jorn Rüsen (2014), em que se traz à tona um aumento da "[...] experiência do passado humano, tanto como um aumento da competência histórica que dá significado a esta experiência, e na capacidade de aplicar estes significados históricos aos quadros de orientação na vida prática".

A intenção em envolver os estudantes em todo o processo de ensino, trouxe algumas contribuições para a aula de história, em que foi possível perceber a dificuldades dos estudantes em interpretar as fontes históricas, ler as mudanças apresentadas nas imagens, e narrar o processo de manutenção do patrimônio cultural na cidade.

A interpretação da fonte, bem como a fundamentação em torno das mudanças na cidade e da preservação do patrimônio cultural, permitiram a narrativa de diferentes 'olhares' sobre as experiências de conhecer melhor a história de sua cidade, relatando as permanências e modificações no cenário urbano. Pode-se dizer que a proposta permite a constituição de uma memória histórica avivada nas pessoas, fazendo-as pesquisar, interpretar, narrar e orientar-se temporalmente. Para Rüsen (2001), o ensino da história deve estabelecer uma relação dinâmica de conhecimento com o passado, o que significa uma interpretação não linear dos acontecimentos, ou seja, as experiências do passado precisam ser interpretadas em consonância com as experiências do presente.

Segundo Schmidt (2009, p. 37), 
[...] aprender história significa contar a história, isto é, significa narrar o passado a partir da vida no presente. O principal objetivo é elaborar uma orientação relacionada com a construção da identidade de cada um e, também, organizar a própria atuação nas lutas e ações do presente, individual e coletivamente.

E, assim, envolve-se a leitura, interpretação e narrativa sobre as fontes, pois

[...] saber ler fontes históricas diversas, com suportes diversos, com mensagens diversas; saber confrontar as fontes nas suas mensagens, nas suas intenções, na sua validade; saber selecionar as fontes, para confirmação e refutação de hipóteses (descritivas e explicativas); saber entender ou procurar entender o 'nós' e os 'outros', em diferentes tempos, em diferentes espaços; saber levantar novas questões, novas hipóteses a investigar algo que constitui, afinal a essência da progressão do conhecimento. (BARCA, 2001, p. 16).

\section{Memória e Patrimônio: um interlace com a História ensinada}

O ensino de História é confrontado hoje por dois tipos de problemas de narrativa. De um lado, trata-se de uma crítica profunda acerca do domínio da narrativa pelos professores em aulas de História, e sobre a tentativa de pôr em prática, no lugar desta, outras formas narrativas de comunicação. De outro lado, é a teoria da narratividade da teoria da História que devemos ter como referência, quando se trabalha e se toma a relação da dependência entre a didática de História e a ciência da História (RÜSEN, 2012, p.33). Com ele podemos, de fato, descrever exatamente o que é a natureza do pensamento histórico, além de outras formas de pensamento. Ele significa a floresta que não podemos ver por causa das grandes árvores (RÜSEN, 2012, p.37). Assim, a narrativa é o processo pelo qual a consciência humana é constituída como consciência história e a História, ao mesmo tempo, é constituída como o conteúdo dessa consciência.

A narrativa está ligada à memória; a memória de sua experiência apresenta a variação temporal da pessoa e seu mundo no passado (que são interpretados em termos de uma experiência do tempo presente). Por meio da narrativa, a experiência do passado é interpretada como que indicando que, no presente, as mudanças experienciadas ao longo do tempo são entendidas e 
espera-se, no futuro, a formação de uma perspectiva de ação. Segundo Rüsen (1992, 2001), a consciência histórica relaciona "ser" (identidade) e "dever" (ação) em uma narrativa significativa que toma os acontecimentos do passado com o objetivo de dar identidade aos sujeitos a partir de suas experiências individuais e coletivas e de tornar inteligível o seu presente, conferindo uma expectativa futura a essa atividade atual. A memória torna o passado significativo, o mantém vivo, e o torna uma parte essencial da orientação cultural da vida presente. A História é uma forma elaborada de memória, pois vai além dos limites de uma vida individual. Trama as peças do passado, rememorando em uma unidade temporal aberta para o futuro, oferecendo às pessoas uma interpretação da mudança temporal (RÜSEN, 2009, p 164).

O discurso sobre a consciência histórica inclui a racionalidade nos procedimentos de produção de sentido do espírito humano. A memória apresenta o passado como uma força móvel do espírito humano guiado pelos princípios do uso prático, enquanto a consciência histórica representa o passado em um interrelacionamento mais explícito com o presente, guiado por conceitos de mudança temporal e reivindicações de verdade; ele reforça a especificidade temporal do passado como uma condição para sua relevância no presente. A memória histórica e o pensamento histórico desempenham essa função de formar identidade em uma perspectiva temporal.

Os estudos sobre a aprendizagem histórica seguem uma metodologia científica e analisam desempenhos concretos de alunos, em tarefas cuidadosamente desenhadas, com materiais históricos e instrumentos didáticos. A reflexão e a expressão de um pensamento crítico sobre o patrimônio podem ser estimuladas, nas crianças e jovens, a partir da utilização de materiais adequados, inteligíveis e motivadores. Umas das condições é que as experiências de aprendizagem se desenvolvam com a utilização dos bens culturais originais: monumentos, arquiteturas, fontes de arquivo, peças de museus, sítios arqueológicos, quadros autênticos, etc. A segunda condição, é que sejam objeto de observação e de uso para produzir informações. A terceira condição, é que eles sejam colocados em relação com o contexto, e com a instituição que os tutela. A quarta condição, é que se promova a tomada de consciência de que são a minúscula parte de um conjunto muito mais amplo, o qual permite o 
conhecimento do passado e do mundo, o prazer de conhecer, a fruição estética. As últimas duas condições requerem que se generalize a descoberta do valor dos bens culturais usados, e das instituições e sujeitos que os tutelam e os estudam.

A partir da experiência e do contato direto com as evidências e manifestações da cultura, em todos os seus múltiplos aspectos, sentidos e significados, o trabalho da Educação Patrimonial busca levar as crianças e adultos a um processo ativo de conhecimento, apropriação e valorização de sua herança cultural, capacitando-os para um melhor usufruto destes bens, propiciando a geração e a produção de novos conhecimentos, num processo contínuo de criação cultural. A observação direta e a análise das "evidências" (aquilo que está à vista de nossos olhos) culturais permitem, à criança ou ao adulto, vivenciar a experiência e o método dos cientistas, dos historiadores, dos arqueólogos, que partem dos fenômenos encontrados, e da análise de seus elementos materiais, formais e funcionais, para chegar a conclusões que sustentam suas teorias.

\section{Referências}

BARCA, Isabel. Educação histórica: uma nova área de investigação. Revista faculdade de Letras e História, Porto, III série, v. 2, p. 13-21, 2001.

BARCA, Isabel. Aula Oficina: do projecto à avaliação. In: . (Org.). Para uma educação histórica de qualidade. Braga: Universidade do Minho, 2004. p.131-144.

Ideias chave para a educação histórica: uma busca de (inter) identidades. História Revista, Goiânia, v. 17, n. 1, p. 37-51, jan./jun. 2012.

BRASIL. Ministério da Educação. Parâmetros curriculares nacionais: história e geografia. 2. ed. Rio de Janeiro: DP\&A, 2000.

COELHO, Alexandra Prado. Rua de Entrecampos, Quando a minha rua era uma aldeia Quintas. Ilustração Mónica Cid. 2015. Disponível em:

<https://www.publico.pt/2015/12/06/local/cronica_urbana/quando-a-minharua-era-uma-aldeia-1716448>. Acesso em: 8 jul. 2017.

DIAS, Alice Gomes et al. Percepção Ambiental Do Patrimônio HistóricoArquitetônico De Três Lagoas/Ms: Um Estudo De Caso Da Igreja Santo Antônio. Campo Grande: Associação de Ensino e Cultura de Mato Grosso do Sul, 2006. 
EHLKE, T. G. Patrimônio Imaterial e Educação Histórica. Setor de EducaçãoDTPEN, 2008. Disponível em: <www.diaadiaeducacao.pr.gov.br>. Acesso em: 18 maio 2016.

GONÇALVES, José Reginaldo Santos. Monumentalidade e cotidiano: Os patrimônios culturais como gênero do discurso. In: OLIVEIRA, Lucia Lipp (Org.). Cidade: História e Desafios. Rio de Janeiro: Ed. FGV, 2002.

HORTA, Maria de Lourdes Parreiras; GRUNBERG, Evelina; MONTEIRO, Adriane Queiroz. Guia Básico de Educação Patrimonial. Brasília: IPHAN/Museu Imperial, 1999.

2000.

Educação Patrimonial: a multiplicação do método. Brasília: IPHAN, . Educação Patrimonial: Histórico, conceitos e processos. Brasília: IPHAN, 2004

IPHAN. Instituto do Patrimônio Histórico e Artístico Nacional. O registro do patrimônio imaterial. 1999. Disponível em: <www.iphan.gov.br/bens/ P.\%20Imaterial/imaterial.htm>. Acesso em: 20 mar. 2016.

. Decreto No 3.551/2000. Institui o Registro de Bens Culturais de Natureza Imaterial que constituem patrimônio cultural brasileiro, cria o Programa Nacional do Patrimônio Imaterial e dá outras providências. 2000. Disponível em: <http://www.camara.gov.br/sileg/integras/ 279736.pdf>. Acesso em: 10 jan. 2016.

LE GOFF, Jacques. História e Memória. Campinas: Editora da UNICAMP, 1996.

LEE, Peter. Progressão da compreensão dos alunos em história. In: BARCA, I. (Org.). Perspectivas em educação histórica. Braga: CEEP, Universidade do Minho, 2001. p. 13-27.

LEE, P. Nós fabricamos carros e eles tinham que andar a pé: compreensão das pessoas do passado. In: BARCA, I. (Org.). Educação histórica e museus. Braga: CIED, Universidade do Minho, 2003.

LEMOS, Carlos A .C. O Que é Patrimônio Histórico. São Paulo: Brasiliense, 1987.

NORA, Pierre. Entre memória e história: a problemática dos lugares. Projeto história, São Paulo, n. 10, p. 7-28, dez., 1993.

OLIVEIRA, Almir Félix Batista de. Patrimônio, memória e ensino de história. In: OLIVEIRA, Margarida Maria Dias de; CAINELLI, Marlenne Rosa; OLIVEIRA, Almir Félix Batista de.(Org.). Ensino de história: múltiplos ensinos em múltiplos espaços. Natal/RN: EDFURN, 2008.

ORIÁ, Ricardo. Memória e ensino de História. In: BITTENCOURT, Circe. O saber Histórico em sala de aula. São Paulo: Contexto, 2005. p.128-148.

PINTO, Helena. Interpretação de fontes patrimoniais em educação histórica. História \& Ensino, Londrina, v. 18, n. 1, p. 187-218, jan./jun. 2012 
RÜSEN, Jörn. Como dar sentido ao passado: questões relevantes de metahistória. História da Historiografia, Rio de Janeiro, n.2, p.163-209, mar. 2009. El desarrollo de la competencia narrativa en el aprendizaje histórico: una hipótesis ontogenética relativa a la conciencia moral. Trad. Silvia Finocchio. Propuesta Educativa, Argentina, n.7, p. 27-37, out. 1992.

Razão histórica: teoria da história; os fundamentos da ciência histórica. Brasília: UNB, 2001. História Viva: teoria da história: formas e funções do conhecimento histórico. Brasília: UnB, 2007. Aprendizagem histórica: fundamentos e paradigmas. Curitiba: W.A. Editores, 2012. Cultura faz sentido: orientações entre o ontem e o amanhã. Tradução de Nélio Schneider. Petrópolis: Vozes, 2014.

SCHMIDT, Maria Auxiliadora. Cognição histórica situada: que aprendizagem histórica é esta? In: SCHMIDT, Maria Auxiliadora; BARCA, Isabel (Org). Aprender História: perspectivas da educação histórica. Ijuí: Editora UNIJUI, 2009. p.117137. 